\title{
Modelo Hélice Tríplice: um mecanismo econômico e ideológico para concretizar os interesses do capital
}

\author{
Triple Helix model: economic and ideological mechanisms to \\ materialize the interests of the capital
}

\author{
Deise Luiza da Silva Ferraz ${ }^{1}$ \\ Valéria Bonadia Marucchi Martoni ${ }^{2}$ \\ Daniela Chamberlai ${ }^{3}$
}

\begin{abstract}
Resumo
Este ensaio enfoca o processo de produção de conhecimento científico nas universidades e sua associação com os interesses do capital. Objetivando elaborar reflexões acerca do modelo conhecido como Hélice Tríplice, o qual contempla a parceria entre academia-empresa-governo, defendemos que o fundo público atua como um mecanismo econômico e ideológico que possibilita concretizar os interesses do capital. A elaboração deste ensaio foi concebida conforme entendimento e discussões de Tragtenberg e Oliveira sobre as relações entre o Estado e a iniciativa privada. O intuito é demonstrar que a (re)distribuição do fundo público tende a ser destinada ao atendimento dos interesses da classe capitalista, em função da própria natureza do Estado, que se revela no modelo Hélice Tríplice: academia-empresa-governo atuando sobre um mesmo eixo (interesses privados). A implementação do modelo Hélice Tríplice precisa ser analisada a partir da leitura materialista dialética e para além das suas formas de manifestação, a fim de evidenciarmos a necessidade de intensificar as disputas pelo fundo público para a
\end{abstract}

\footnotetext{
${ }^{1}$ Doutora, Mestra e Bacharela em Administração pela Universidade Federal do Rio Grande do Sul, com um período de estágio-doutoral no Centro de Investigação em Sociologia Econômica e das Organizações (SOCIUS) do Instituto Superior de Economia e Gestão da Universidade Técnica de Lisboa. Professora, pesquisadora e orientadora no Programa de Mestrado Interdisciplinar em Organizações e Desenvolvimento da FAE - Centro Universitário (PMOD/FAE). Pesquisadora Júnior IPEA/CAPES, Pesquisadora dos seguintes grupos de pesquisa: SOCIUS (ISEG/UTL), Economia Política do Poder em Estudos Organizacionais (UFPR/CAPES). Coordenadora de Projetos de Pesquisas financiados por órgãos nacionais de fomento (CNPQ, edital 020/2010 - Processo: 402541/2010-3 e IPEA/CAPES, edital 01/2010 - Processo 177/2010). Trabalho de forma interdisciplinar com as seguintes áreas científias: Sociologia, Antropologia, Psicologia, Economia e Administração. E-mail: deiseluizaferraz@gmail.com.

${ }_{2}$ Mestranda no Programa de Mestrado Interdisciplinar em Organizações e Desenvolvimento da FAE Centro Universitário (PMOD/FAE). Possui graduação em Administração pela Universidade Estadual de Maringá (2002). Especialização em MBA Finanças, pelo Centro de Ensino Superior de Maringá (2006). Atualmente é Administradora na Universidade Federal de Ouro Preto. E-mail: vmarucchi@gmail.com

${ }^{3}$ Mestranda no Programa de Mestrado Interdisciplinar em Organizações e Desenvolvimento da FAE Centro Universitário (PMOD/FAE). Graduação em Direito pela Pontifícia Universidade Católica do Paraná, Brasil (2000). Advogada do Grupo Frischmann's, Brasil. E-mail: dani_chamber@yahoo.com.br.
}

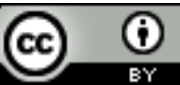

Esta obra foi licenciada com uma Licença Creative Commons - Atribuição 3.0 Não Adaptada. 
construção de conhecimentos e tecnologias que estejam a serviço da emancipação humana e não da perpetuação de sua alienação.

Palavras-chave: Hélice tríplice. Interesses do Capital. Fundo Público. Academia.

\begin{abstract}
This essay focuses on the production process of scientific knowledge in universities and its association with interests of capital. Our aim is to reflect about the model known as Triple Helix, including the association between academy, firms and government. We advocate that the public fund acts like an economic and ideological mechanism, which enables to carry out the interests of capital. The preparation of this essay was conceived under the Tragtenberg and Oliveira discussions about relations between State and private initiative. Our goal is to show that the (re)distribution of public funds tends to be destined to benefit the capitalist class. This occurs due to the nature of State in Triple Helix model, i.e. academy, firms and government acting to the same end (private interests). The Triple Helix model implementation needs to be analyzed from a dialectic materialistic reading and beyond its manifestation forms. It is necessary to intensify competition for the application of public funds geared towards knowledge and technologies that will serve human emancipation rather than perpetuate alienation.
\end{abstract}

Key words: Triple helix. Interests of capital. Public fund. Academy.

\title{
1 Introdução
}

Intensifica-se, no Brasil, o processo de produção de conhecimento científico. As universidades, por meio de seu corpo acadêmico, têm sido um grande sujeito desse processo. Um modelo que impulsiona tal produtividade é conhecido como Hélice Tríplice, ou seja, a parceria academia-empresa-governo. Segundo Borges (2010) essa é a forma de garantir que os recursos públicos retornem à sociedade, seja na forma de novos produtos, de empregos ou na geração de riqueza que vise a uma melhor qualidade de vida.

O modelo Hélice Tríplice, portanto, hodiernamente, é responsável por estear, concomitantemente, dois dos pés do tripé que funda a concepção de Universidade, qual seja: pesquisa e extensão. Aquele modelo, pela parceria UniversidadeEmpresa, consentida e incentivada pelo Estado, dá propulsão ao desenvolvimento de pesquisas e, por via de regra, de construção do conhecimento. Eis a sustentação do "pé" pesquisa.

Por sua vez, a concepção clássica de universidade atribui à extensão a função de retornar à sociedade os investimentos realizados em pesquisas e na qualificação profissional dos distintos membros da comunidade acadêmica 
(docentes, técnicos e discentes). Para assegurar o retorno social da universidade, o modelo Hélice Tríplice insere o conceito de inovação tecnológica. Em geral, esse conceito especifica a hélice Empresa como destinatária da inovação. Com isso, configura-se a inserção de um mediador entre a comunidade acadêmica e a sociedade em geral: a empresa. Essa mediação manifesta-se de forma sutil, não substitui o denominado departamento de extensão e seus projetos, por vezes, usase desse para garantir o retorno social, mas procura substituir a sociedade, ou, nas palavras de seus defensores, garantir que a universidade retorne à sociedade o que é de seu interesse e, nesse sentido, as empresas passam a ser portadoras particulares dos interesses gerais. A questão que se impõe na instituição desse mediador é: como se processa o movimento de particularização dos interesses gerais da sociedade no ente privado?

Para buscar respostas a essa questão, recorremos aos escritos de dois pensadores brasileiros: Maurício Tragtenberg e Francisco de Oliveira. Reconhecemos a complexidade do debate e, nesse sentido, não é nosso objetivo esgotar o tema, mas apenas elaborar reflexões, na forma de um ensaio, sobre a operacionalização do modelo, com a finalidade de defendermos que o fundo público atua, por meio do modelo da Hélice Tríplice, como um mecanismo econômico e ideológico que possibilita concretizar os interesses do capital.

As considerações de Oliveira e Tragtenberg acerca das relações entre o Estado e as iniciativas privadas enquanto ente jurídico empresa se aproximam, e a predominância da abordagem econômica nos escritos do primeiro e da sociológica, no segundo, se complementam para a compreensão interdisciplinar das relações sociais necessárias à produção de um determinado conhecimento científico que atua tanto como alavanca da produção, centralização e acumulação do capital, quanto como substrato de sua legitimação.

\section{Procedimentos metodológicos da construção do argumento}

Para a elaboração deste texto, torna-se necessário um levantamento bibliográfico e uma leitura seletiva e interpretativa de autores da economia política, história, sociologia, entre outros. A partir do arcabouço teórico-filosófico é realizado 
um estudo referente aos escritos de dois pensadores brasileiros: Maurício Tragtenberg e Francisco de Oliveira.

A elaboração deste artigo foi concebida conforme o entendimento de Tragtenberg (2006, p. 21), para o qual um ensaio é também "uma interpretação e associação nova de idéias, fundadas em 'antigos' textos". Nesse sentido, amparados pela discussão que Oliveira faz sobre o fundo público enquanto elemento estrutural do movimento de acumulação do capital; e, de Tragtenberg, que considera a relação entre o Estado e as Corporações uma necessidade para a produção de um saber que perpetua o poder de um grupo dominante, defendemos aquela assertiva sobre $o$ duplo papel do fundo público.

Parte-se do princípio que os fatos sociais não podem ser analisados isoladamente da conjuntura histórica, social e econômica, sem a devida observação das relações sociais estabelecidas no processo de produção da vida material, necessitando desvendar as leis do movimento do capital. Assim a construção teórica será elaborada tendo como método teórico filosófico o Materialismo Histórico e Dialético.

A preocupação em entender a relação entre as iniciativas econômicas privadas e o Estado é central para Oliveira, que em seu livro Os Direitos do Antivalor (1998) defende a tese de que o fundo público é elemento estruturante e pressuposto do financiamento da acumulação do capital, seja ao atuar como um antivalor, seja por possibilitar a desmercantilização da força de trabalho. Por sua vez, encontramos nos diversos escritos de Tragtenberg a intenção de compreender a relação entre as corporações e o Estado na produção de um saber que reproduz a dominação: tratase da produção de um conhecimento científico para o fornecimento de um substrato ideológico. Assim, pretendemos efetuar um diálogo com os escritos desses pensadores partindo de considerações sobre algumas medidas adotadas para a implementação do modelo Hélice Tríplice, problematizando, ao final deste texto, a questão supracitada enquanto um falso problema, sobretudo em função da discussão marxiana sobre a natureza do Estado. 


\section{Francisco de Oliveira: apresentando o Fundo Público enquanto mecanismo econômico}

Francisco de Oliveira (1998) discute a nova natureza e o destino estratégico dado aos fundos públicos, a partir dos anos 30 do século passado e, em particular, depois da Segunda Guerra Mundial, pois segundo ele, após esse momento histórico, a acumulação do capital passou a prescindir do financiamento de recursos públicos para a sua valorização e dos gastos considerados sociais para o financiamento da reprodução da força de trabalho. Para o autor, o atual sistema capitalista seria impensável sem a utilização dos recursos públicos, sendo que a própria formação da taxa de lucro passa por ele, tornando-o um componente estrutural insubstituível, assim como a outorga para o financiamento público de parcelas da reprodução da força de trabalho é uma tendência histórica no sistema capitalista.

Vale destacar que o autor foca as análises nos países onde, de uma forma ou outra, houve um significativo desenvolvimento do welfare state. Ele cita, por exemplo, o aumento das despesas públicas, entre os anos de 1960 a 1984, nos países partícipes da Organização para Cooperação e Desenvolvimento Econômico (OCDE). Em programas voltados à educação e saúde os investimentos passaram de $14 \%$ à aproximadamente $25 \%$ do PIB.

Segundo Oliveira, a internacionalização produtiva e financeira da economia capitalista fez romper o círculo perfeito de retroalimentação do Estado-providência, gerando o déficit público e sua crise, pois o padrão de financiamento público não pode se desterritorializar mas, por sua vez, a renda e os investimentos sim, ou seja, o Estado passou a arrecadar menos com os ganhos fiscais, mas seu papel de articulador e financiador da reprodução do capital e da força de trabalho continuou igual.

Para o autor, existe um indisfarçável acento ideológico na crítica a essa crise quando se faz forte ligação dela à produção de bens sociais públicos e minimiza a associação da presença dos fundos públicos na estruturação da reprodução do capital. Ademais, Oliveira destaca que os países em que a dívida pública é em média a metade do seu PIB, são "indiscutivelmente, as mais notáveis lideranças industriais, tecnológicas e financeiras do capitalismo contemporâneo" (OLIVEIRA, 1998, p. 25). 
O fundo público agiliza a circulação do capital, através de vários tipos de incentivos, subsídios e, também, na forma de títulos públicos. Ele influi decisivamente, por exemplo, na formação da taxa média de lucros do setor oligopolista, no desenvolvimento de pesquisas de ponta, em programas especiais de produção, como o aeronáutico, a informática, o agrícola etc. Mas também influi pelo negativo, pela sua ausência, na manutenção de capitais e capitalistas no circuito que o autor chamou de setor concorrência primitivo. O fato é que a taxa de lucro do capitalista privado deveria fazer referência simultaneamente ao seu próprio capital e à fração dos fundos públicos utilizados para sua reprodução. Desse movimento resulta que, enquanto cada capital em particular tem sua taxa de lucro aumentada, diminui-se a taxa de excedente global da economia. A explicação para isso: a fração do fundo público ou não tem remuneração ou esta é subestimada, de modo que o capital procedente do fundo público atua como um anti-capital, pois não visa a valorização de si.

Ademais, como o fundo público tornou-se um elemento estrutural, criou-se uma relação direta entre ele e a taxa de lucro (de retorno) de determinados setores da economia. O fundo público opera como expressão da taxa de lucro, como parte dela, pois é a partir dela que cada capital particular estará relacionado. A necessidade do fundo público enquanto mecanismo estrutural de valorização do capital, seja pelo subsídio ao capital ou pela desmercantilização de parte da força de trabalho, está relacionado ao próprio limite do capital, de tal modo, ele se comporta como antivalor menos no sentido de não produtor de valor e "mais no sentido de que os pressupostos da reprodução do valor contêm, em si mesmo, os elementos mais fundamentais de sua negação" (OLIVERIA, 1998, p. 35). Oliveira continua:

\begin{abstract}
O fundo público, portanto, busca explicar a constituição, a formação de uma nova sustentação da produção e da reprodução do valor, introduzindo, mixando, na mesma unidade, a forma valor e o antivalor, isto é, um valor que busca a mais-valia e o lucro, e uma outra fração, que chamo antivalor, que por não buscar se valorizar per si, pois não é capital, ao juntar-se ao capital, sustenta o processo de valorização do capital (ibidem, p. 53).
\end{abstract}

Um exemplo concreto da ação do fundo público pode ser encontrado em experiências como o do Fundopem no Rio Grande do Sul. O Fundopem é um instrumento de renúncia fiscal, especificamente do Imposto Sobre Circulação de Mercadorias e Serviços (ICMS), o mais expressivo na receita total de arrecadação

Cad. de Pesq. Interdisc. em Ci-s. Hum-s., Florianópolis, v.13, n.103, p.115-145, ago/dez 2012 
do estado, e corresponde à aproximadamente $75 \%$ das receitas. Segundo Kapron e Lengler (2006, p. 4-5):

\begin{abstract}
As empresas devem recolher o tributo em função da comercialização de seus produtos ou serviços. De fato, o tributo é cobrado do consumidor, cabendo à empresa repassar os respectivos valores aos cofres públicos. $O$ Fundopem consiste em permitir que a empresa fique com o tributo (ou parte dele) em troca de investimentos que incrementem a produção e o emprego. [...] Um novo formato da legislação aprovado no ano de 1997 introduziu a modalidade de financiamento. As empresas agora deveriam devolver os recursos aos cofres públicos (até então era a fundo perdido) após um período de até 05 anos de carência e com 08 anos de amortização, com juros de até $6 \%$ ao ano e com a possibilidade de correção de no máximo $90 \%$ da inflação. A modalidade de fundo perdido retorna na legislação de 2003 , agora sob a forma de um abatimento em parte do retorno do valor financiado, mas dirigido a investimentos que fossem realizados em regiões com menores índices de desenvolvimento social, salvo exceções que fossem julgadas durante a concessão.
\end{abstract}

$\mathrm{Na}$ década de 1990 tem início a intensificação do uso desse Fundo. Os empresários, que aprovam seus projetos, devem deixar de recolher um determinado montante aos cofres públicos durante um período de cinco anos. No final daquela década, o estado começou a sentir o impacto dessa política, mas é nessa mesma época em que são concedidos os maiores incentivos. A agudização do déficit na arrecadação será percebida em 1999, conforme gráfico 1.

Kapron e Lengler (2006) ponderam que o uso do Fundo para incentivar o investimento privado com verbas públicas, além de efetivar uma concorrência "desleal", por estabelecer a concorrência entre as empresas que não tributam e as que tributam, não altera o quadro do mercado de trabalho. Gielh (2001), por sua vez, acrescenta que não há sequer a desconcentração industrial, uma das justificativas para a aprovação da lei, pois $74 \%$ das empresas beneficiadas pelo Fundo, até o ano de 2000, eram da Macro-Região Nordeste, eixo mais industrializado do estado, que inclui as seguintes regiões, segundo dados do IBGE: Metropolitana de Porto Alegre, Litoral, Vale dos Sinos, Vale do Caí, Vale do Taquari, Serra, Hortênsia e Paranhana. 


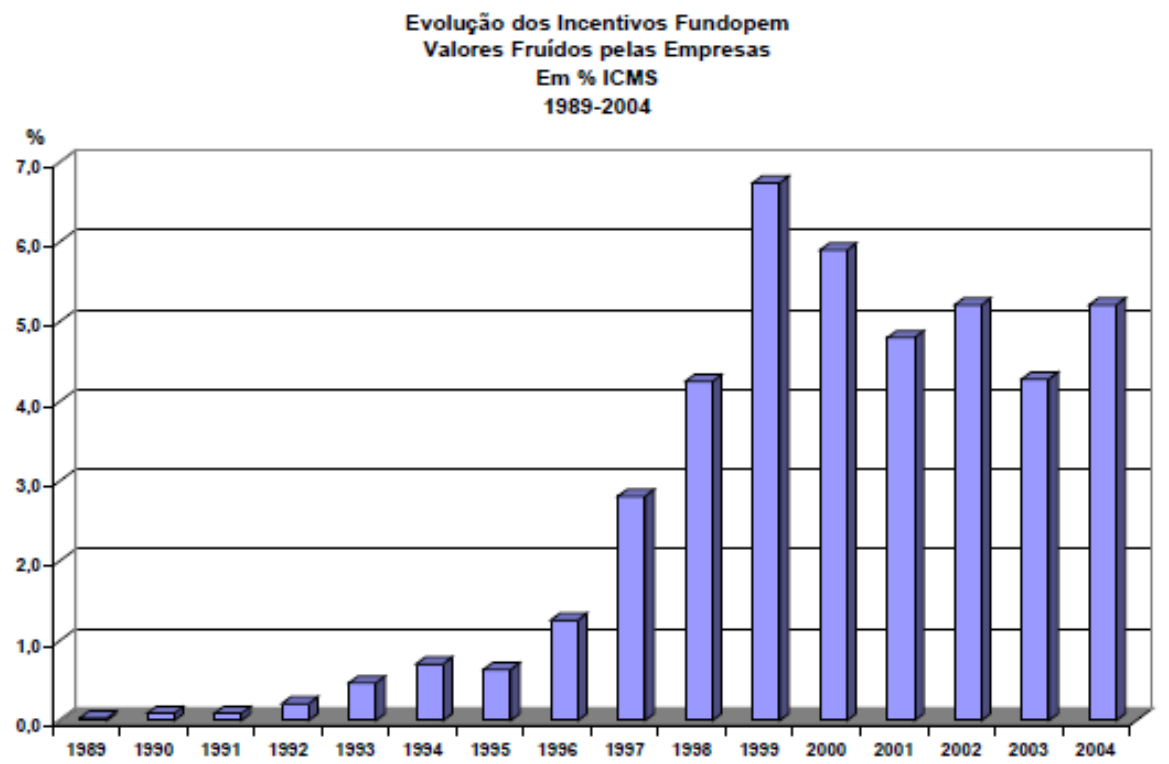

Gráfico 1: Evolução dos incentivos Fundopem

Fonte: Kapron e Lengler (2006)

O setor de bebidas é um exemplo emblemático, pois se utilizou do benefício e não efetuou a industrialização descentralizada. Aliás, pelo contrário, efetuou uma relativa desindustrialização de algumas regiões, bem como não gerou empregos as duas grandes justificativas utilizadas para obter apoio público no que tange à importância da concessão do fundo. No caso desse setor, a Brahma recebeu o incentivo, acrescido de outras vantagens, para instalar uma planta produtiva em Viamão, região Metropolitana de Porto Alegre (convênio assinado em 1996). A vinda de mais uma unidade dessa empresa para o estado prometia a criação de centenas de postos de trabalho diretos e indiretos. Em 1998, a cervejaria é inaugurada tendo em sua folha de pagamento 400 empregados. No mesmo ano, duas empresas do setor encerram suas atividades: a Skol, localizada em Passo Fundo, e a própria fábrica da Brahma localizada em Porto Alegre. Juntas demitiram 700 pessoas. Os anos que seguiram foram de mais falências, fusões e demissões. No total, sete cervejarias fecharam entre os anos de 1996 e 2006 em todo estado, demitindo aproximadamente mais de 500 trabalhadores. Kapron e Lengler (2006) destacam que dois dos setores mais incentivados entre os anos 1994 e 2004, fumos e bebidas, receberam juntos 1,3 bilhões de reais em incentivos, mas acumularam uma alteração de 2,4 pontos percentuais negativos nos postos de trabalho, o que significa, em números absolutos, 2117 desempregados. Os autores demonstram, Cad. de Pesq. Interdisc. em Ci-s. Hum-s., Florianópolis, v.13, n.103, p.115-145, ago/dez 2012 
após análise comparativa entre os setores incentivados e não-incentivados, que: "[...] não se verifica nenhuma mudança estrutural significativa na participação nos empregos totais entre os setores mais incentivados pelo Fundopem" (KAPRON e LENGLER, 2006, p. 11-12).

Ponderamos, a partir das teorizações de Oliveira e dos dados apresentados pelos autores supracitados, que o dinheiro público, ou melhor, o produto social do trabalho, que deveria ser apropriado pelo Estado, é (re)apropriado por empresas privadas de diferentes setores da economia gaúcha e, ao invés de gerar os empregos via ampliação da produção, foi destinado ao aumento da produtividade do trabalho, por meio da introdução de novas tecnologias físicas e de gestão, uma vez que o período que se estende de 1994 a 2003 é caracterizado, sobretudo, pela conhecida reestruturação produtiva. Temos, dessa forma, um Fundo que funciona como mecanismo de financiamento da reestruturação, de aumento da produtividade, que impacta negativamente sobre a demanda por trabalhadores. O fundo público, portanto, conforme demonstrado nesse exemplo, atuou como elemento estrutural da acumulação do capital, que determina a taxa de lucro de capitais particulares, reduz a taxa de lucro média - por meio da concorrência desleal - e, por outro lado, é incapaz de gerar novas necessidades de mão-de-obra e de desmercantilizar a força de trabalho, por meio dos gastos sociais, como ocorreu nos países da OCDE, conforme análise de Oliveira sobre os mesmos.

Para esse autor, em relação à reprodução da força de trabalho, o fundo público naqueles países opera através do financiamento público de bens e serviços sociais. As políticas, no estado do bem estar social, foram no sentido de aumentar a participação do salário indireto no salário total, de modo que estes bens e serviços atuassem como antimercadorias sociais, pois sua finalidade não é a de gerar lucro, nem através de sua ação extrai-se a mais-valia.

De fato, indexando os benefícios sociais ao salário, o que se está fazendo é tornar o salário o parâmetro básico da produção de bens e serviços sociais públicos. Isto é o oposto da extração da mais-valia e, consequentemente, em sua derivação, da determinação da taxa de lucro, onde os parâmetros não apenas do cálculo mas da razão da mais-valia residem na relação capital constante - capital variável, sendo que "[...] há, teoricamente, uma tendência à des-mercantilização da força de trabalho 
pelo fato de que os componentes de sua reprodução representados pelo salário indireto são antimercadorias sociais" (OLIVEIRA, 1998, p. 30, grifo nosso).

Contudo, analisando o caso brasileiro, citado anteriormente, o incentivo público destinado ao setor privado além de não ter gerado os empregos esperados reduziu os investimentos públicos em função da diminuição da receita fiscal. Quando considerado os investimentos efetuados pelo governo do estado sem a mediação da apropriação direta pela iniciativa privada, percebemos que eles, ao longo do período considerado, decrescem enquanto as renúncias fiscais aumentam. Em 2004, por exemplo, o investimento público reduziu-se em aproximadamente 650 milhões de reais, enquanto que a renúncia fiscal era da ordem de aproximadamente 500 milhões. Kapron e Lengler (2006) concluem que o não recolhimento do ICMS aos cofres públicos, além de diminuir a capacidade de investimento do estado, ainda não gera os respectivos empregos prometidos.

O fundo público, portanto, é um elemento estrutural no movimento da acumulação do capital, mas não atua de forma proporcional na desmercantilização da força de trabalho, em função do reduzido investimento do Estado brasileiro nos bens e serviços públicos. Os gastos públicos com saúde representam apenas 4,8\% do PIB, enquanto que o gasto com educação representa 4,1\% nos anos de 2004 e 2005, respectivamente (IBGE, s/d).

Nesse sentido, no Brasil, aliado ao baixo investimento com bens e serviços sociais, que não permite reproduzir o patamar de desmercantilização da força de trabalho dos países europeus que compõem a OCDE, temos tais bens e serviços tornando-se mercadoria via, por exemplo, planos de saúde e ensino privado. Porém, vale ressaltar que a mercantilização desses bens também se vale do fundo público para a valorização do capital. Assim, concordamos com Oliveira (1998) que afirma estar o fundo público presente na reprodução simultânea do capital e da força de trabalho, como financiador da cultura, da saúde e da educação.

Outro ponto destacado por Oliveira, em sua análise do movimento de acumulação do capital em países capitalistas desenvolvidos, é o efeito da desmercantilização da força de trabalho na inovação técnica. Esta se desparametrizou do salário real total, posto que o salário indireto tornou-se um componente não desprezível daquele, e assim deslanchou-se um processo de inovações tecnológicas sem precedentes. 
O que torna o fundo público estrutural e insubstituível no processo de acumulação de capital, atuando nas duas pontas de sua constituição, é que sua mediação é absolutamente necessária pelo fato de que, tendo desatado o capital de suas determinações autovalorizáveis, detonou um agigantamento das forças produtivas de tal forma que o lucro capitalista é absolutamente insuficiente para dar forma, concretizar, as novas possibilidades de progresso técnico abertas (OLIVEIRA, 1998, p. 31, grifo do autor). Disto decorre que o parâmetro para se medir a valorização do capital é agora um mix, onde o fundo público não entra como valor, e o preço da mão de obra da força de trabalho é indiferente do ponto de vista das inovações técnicas.

Com o crescimento colossal das forças produtivas, o lucro capitalista não consegue, per si, concretizar as novas possibilidades de progresso técnico abertas, sendo a solução para esse problema a apropriação dos recursos públicos, da riqueza pública geral, que nas economias capitalistas tomam a forma estatal. Mas a contradição apontada por Oliveira (1998) é que enquanto se vê o aumento da rentabilidade, ou das taxas de retorno dos capitais - fazendo enriquecer os setores privados -, o fundo público, o qual contribui para esse enriquecimento, dá sinais de esgotamento, como na redução dos gastos sociais ocorridos no Rio Grande do Sul.

É importante destacar que a desparametrização da inovação técnica com o salário, no Brasil, é uma característica particular do modo de desenvolvimento do sociometabolismo do capital presente antes mesmo de uma suposta desmercantilização que poderia ter ocorrido de forma substancial em função da efetividade dos direitos presentes na Constituição Brasileira. O próprio Francisco de Oliveira, na Crítica a Razão Dualista / O Ornitorrinco (2003), menciona que a superexploração da mão de obra no Brasil permite a simbiose entre mais-valia absoluta e mais-valia relativa. Segundo o autor, a vantagem do movimento de acumulação do capital em países como o Brasil, reside no fato de que

\footnotetext{
o processo de reprodução do capital "queima" várias etapas, entre as quais a mais importante é não precisar esperar que o preço da força de trabalho se tornar suficientemente alto para introduzir as transformações tecnológicas que economizam trabalho (OLIVEIRA, 2003, p. 67).
}

Destacamos que tais tecnologias tanto são importadas quanto desenvolvidas em terras brasilis com o incentivo do fundo público. 
Para Oliveira, a tarefa da esfera pública é a de criar medidas tendo como desígnios as diversas necessidades da reprodução do social, em todos os sentidos, "é a necessidade, por exemplo, da reprodução do capital em setores que, por sua própria lógica, talvez não tivessem capacidade de reproduzir-se" (OLIVEIRA, 1998, p. 40). Segundo ele, podem ser necessidades de vários tipos, das quais destaca o desenvolvimento científico e tecnológico que não podem depender unicamente de nenhum capital em especial. Tal tarefa tem sido efetuada por meio do modelo Hélice Tríplice. Observando tanto os mecanismos legais que possibilitam a atuação do elemento estrutural fundo público no desenvolvimento do conhecimento voltado à inovação tecnológica, quanto um exemplo (ainda que sumariamente apresentado) da operacionalização via implantação de uma Incubadora Tecnológica, buscamos verificar a mediação da empresa na relação Universidade - Sociedade.

\section{Fundo Público: possibilitando a mediação da hélice empresa}

Em 2004 foi sancionada a Lei $n^{\circ} 10.973 / 2004$, que dispõe sobre incentivos à inovação e à pesquisa científica e tecnológica no ambiente produtivo, assim como, em 2005, foi sancionado o Decreto 5.563/2005 que a regulamentou. A Lei, conforme seu Art. $1^{\circ}$., visa:

Art. $1^{\circ}$ Esta Lei estabelece medidas de incentivo à inovação e à pesquisa científica e tecnológica no ambiente produtivo, com vistas à capacitação e ao alcance da autonomia tecnológica e ao desenvolvimento industrial do País, nos termos dos arts. 218 e 219 da Constituição. (LEI n ${ }^{0 .}$ 10.973, de 2 de dezembro de 2004).

Ao analisarmos esta Lei, evidencia-se a utilização do modelo Hélice Tríplice, ou seja, a parceria academia-empresa-governo, pois ela preceitua os dispositivos legais para a inclusão de empresas privadas no espaço público e vice-versa, com a possibilidade de compartilhar infraestrutura, equipamentos e recursos humanos. Permite, também, que entidades públicas como as Instituições Científica e Tecnológica (ICTs) contratem ou criem convênios com entidades privadas, inclusive para transferência de tecnologias e de licenciamentos para outorgas de direito de uso ou de exploração de criação por elas desenvolvidas, e para sua comercialização, conforme dispõe o parágrafo $4^{\circ}$ e caput do artigo $6^{\circ}$. 
Ainda, conforme o Artigo 11 da Lei em comento, as ICTs poderão até ceder seus direitos sobre sua criação, desde que obedecidos critérios pré-estabelecidos.

Em seu artigo 19, além da concessão de recursos humanos, materiais e de infraestrutura, a Lei outorga o direito ao governo de dispor inclusive de recursos financeiros ao setor privado para o apoio ao desenvolvimento à inovação e à pesquisa científica e tecnológica no ambiente produtivo.

$\mathrm{Na}$ época da criação e da regulamentação da Lei, o então ministro da Ciência e Tecnologia, Sérgio Rezende fez algumas declarações ressaltando que:

\begin{abstract}
A Lei de Inovação vai facilitar a interação entre as universidades, instituições de pesquisa e o setor produtivo, estimulando o desenvolvimento de produtos e processos inovadores pelas empresas brasileiras, com grande impacto sobre a competitividade do país. (...)

A MP 252, a Lei de Inovação Tecnológica e a regulamentação do Fundo Nacional de Desenvolvimento Científico e Tecnológico (FNDCT) permitirão que as pesquisas de inovação tecnológica cheguem às empresas e não fiquem restritas apenas às universidades (INOVAÇÃO Tecnológica, 2005).
\end{abstract}

Um caso específico retrata a concretização do modelo Hélice Tríplice e seus desdobramentos. Em 2009, foi apresentada ao Conselho Universitário de um Instituto Federal de Ensino Superior, localizado em um estado do sul do país, a proposta de implantação de um Parque Científico e Tecnológico. O texto, após um inventário acerca dos resultados positivos provenientes das pesquisas já realizadas na instituição, afirma:

Todos estes dados mostram que a [UNIVERSIDADE] é uma instituição em que os recursos humanos realizam pesquisa básica e desenvolvimento tecnológico de excelência, com eficiência, contando com uma infra-estrutura de laboratórios, equipamentos e bibliotecas adequada, e que realiza ainda pesquisa e desenvolvimento de produtos e processos inovadores em colaboração com empresas, atendendo assim as prioridades das políticas industriais e tecnológicas municipal, estaduais e nacionais. Estas empresas poderão compartilhar, de maneira mais efetiva do que hoje o fazem, a partir da institucionalização do Parque Científico e Tecnológico da [UNIVERIDADE], destes laboratórios, equipamentos, instrumentos, materiais e demais instalações com a [UNIVERIDADE], além de agir concatenadamente com a capacidade inovativa instalada na [UNIVERIDADE], tornando o processo de interação universidade - empresa muito mais eficiente. [...] O conhecimento científico e tecnológico existente na [UNIVERSIDADE] é a grande âncora que tornará o Parque uma iniciativa de enorme interesse para a comunidade industrial e de serviços (MAULER, et al., 2009, p. 8).

As informações apresentadas nesse texto demonstram que a universidade, com seu corpo docente e discente, está sendo capaz de desenvolver conhecimento, 
tecnologias e produtos inovadores, dessa forma, é patente que há o que ser transferido. Disso, algumas questões se impõem enquanto problemática para agendas de pesquisa: por que a própria universidade não possibilita a melhora na qualidade de vida do cidadão repassando esse conhecimento e inovações para a esfera pública? Se o Estado tem sustentado a produção do saber e da inovação, por que não o apropriar para a efetivação de um desenvolvimento mais equitativo? Em outras palavras, por que é preciso confiar na empresa privada para ser agente do desenvolvimento?

Como podemos verificar, a missão de tal Parque resume-se em transferir tecnologia de pesquisa e desenvolvimento da "Universidade para a sociedade através do setor produtivo e administrar o fluxo de conhecimento e tecnologia entre a Universidade, empresas e mercados" (MAULER et al., 2009, p. 9). O texto não deixa dúvidas quanto o papel mediador da iniciativa privada, bem como não questiona a eficácia do mercado enquanto um agente de desenvolvimento da sociedade ao afirmar que seu primeiro objetivo é: "Criar um ambiente propício e ágil, para a transferência de tecnologia, orientado pela excelência da pesquisa desenvolvida na Universidade, para uso do setor produtivo, gerando riqueza para a região e retorno para a universidade" (MAULER et al., 2009, p. 9).

A descrição sumária dessa proposta e os relatos do ex-ministro, sobretudo o último, remetem à assertiva apresentada na introdução do texto, pois, como podemos observar, a empresa, destinatária do produto desenvolvido nos laboratórios públicos e ICTs, via parceria academia - empresa - governo, garante a efetivação do retorno social das universidades. As iniciativas privadas, na forma jurídica empresa, têm assegurado em lei a possibilidade de representar a sociedade em geral. Isso faz parecer que é apenas por meio delas que o conhecimento científico pode concretizar a efetivação dos interesses gerais, ou, como diria Tragtenberg (2004), a lei regulamenta o interesse particular como o desejável.

Em suma, segundo as considerações de Oliveira, o movimento de acumulação do capital seria insustentável sem o fundo público que o estrutura, seja enquanto alavanca no aumento de taxas de lucros privadas, seja enquanto alavanca dos investimentos em áreas necessárias para o desenvolvimento científico e tecnológico. Assim, de acordo com o segundo exemplo, verificamos que a efetivação do modelo da Hélice Tríplice é uma das formas de operacionalização do 
fundo público enquanto mecanismo econômico que propulsiona a reprodução do capital.

No que tange o desenvolvimento científico e tecnológico, enquanto mecanismo ideológico, recorremos à Tragtenberg, pois este é enfático em demonstrar a relação entre o público e o privado, ou, como o autor prefere tratar, a relação entre os governos e as corporações para a perpetuação das relações de dominação. Vejamos o que nos ensina Tragtenberg.

\section{Maurício Tragtenberg: saber como poder perpetuado pelo fundo público}

Para a elaboração das considerações realizadas nesse item, foram utilizados os textos reunidos nos livros Sobre Educação, Política e Sindicalismo (2004), Administração, Poder e Ideologia (2005) e Burocracia e Ideologia (2006). Os textos escolhidos para compor a primeira obra guardam tamanha verossimilhança com os dias atuais que, abstraindo um ou outro fato histórico que possibilitaram ao autor desenvolver os argumentos centrais à discussão, poderíamos inferir que foram escritos no decorrer do ano vigente, atestando a atualidade do pensamento de Tragtenberg. Um leitor desatento ou pessimista poderia até concluir sua leitura afirmando: sim, as coisas são assim, sempre foram e sempre serão. Triste constatação! Seja porque Tragtenberg desejava frisar justamente o oposto, desconstruir o processo de naturalização, seja porque ratifica que a escola, enquanto lócus privilegiado do processo educacional, segue desenvolvendo o processo da "aceitação do existente como o desejável" (TRAGTENBERG, 2004, p. 68).

Tragtenberg escreveu grande parte dos textos que compõem o livro ainda sob a ditadura militar. Três décadas passaram-se: da ditadura à democracia dos trabalhadores (leia-se do Partido dos Trabalhadores); da produção fordista ao toyotismo como modelo predominante da produção (ALVES, 2000); dos movimentos sociais de massa aos grupos de consulta institucionalizados nos orçamentos participativos; da automação da fábrica ao mundo virtual; de um "milagre econômico" a outro, passando por um largo período de recessão e superexploração dos trabalhadores. Como podem ocorrer tantas mudanças e nada mudar? 
Deslocando a atenção da forma para o conteúdo, podemos perceber que houve alterações e, como um condiciona o outro, não é possível manter a dicotomia mudanças - permanências. A discussão necessita ocorrer sob a insígnia da superação, aqui entendida enquanto síntese de processos contraditórios que suspende a tese e a antítese pela constituição do posteriori gestado no momento ulterior de negação. Posto isso, Tragtenberg (seu pensamento) não foi superado.

O autor, preocupado em entender "em que condições o poder produz um tipo de saber necessário à dominação, e em que medida esse saber aplicado reproduz o poder" (TRAGTENBERG, 2004, p. 21) analisa: 1) os projetos de pesquisa financiados pelo Estado Americano e por bancos internacionais ligados ao desenvolvimento; 2) a nomeação de cientistas para ocupar cadeiras no Departamento de Estado dos Estados Unidos da América; e, 3) a aplicação dos conhecimentos produzidos por essas pesquisas. Ele conclui:

\begin{abstract}
A ciência social vê-se reduzida a simples fornecedora de elementos aos que detêm o poder nos EUA, para permitir a sua intervenção nos aspectos econômicos ou sociais do real [...]. Na medida em que os cientistas propõem terapia de controle sobre os que estão abaixo, eles servem aos que estão acima (TRAGTENBERG, 2004, p. 27).
\end{abstract}

Apresentando sucintamente exemplos da aplicação dos conhecimentos científicos, o autor lembra dos dólares gastos pelo Departamento de Estado para compreender as dinâmicas sociais revolucionárias no Vietnã, do Projeto Manhattan, dos programas universitários interamericanos, protagonizados pela Universidade de Wisconsin, cujo interesse na América Latina era identificar "fatores que possam levar a uma mudança social que não se detenha na modernização pura e simples" (TRAGTENBERG, 2004, p. 36).

Em suma, no livro sobre Educação, Política e Sindicalismo (2004), sobretudo no texto "O Saber e o Poder"4, o autor demonstra através de inúmeros dados a relação existente entre o financiamento de atividades de pesquisa e a necessidade da produção de conhecimentos que são aplicados ou necessários à aplicação de processos de dominação que perpetuem a permanência de determinados grupos no comando da ordem social. Em outras palavras, destaca o condicionamento da

\footnotetext{
${ }^{4}$ Primeira edição em 1978.
}

Cad. de Pesq. Interdisc. em Ci-s. Hum-s., Florianópolis, v.13, n.103, p.115-145, ago/dez 2012 
produção do conhecimento pelas políticas estratégicas que atendem interesses de determinados grupos que ocupam posições de mando e o quanto esse saber é usado para docilizar os comandados, perpetuando as relações de poder entre as classes.

No texto A ideologia Administrativa das Grandes Corporações, publicado no livro Administração, Poder e Ideologia (2005), esses grupos aparecem corporificados sob a insígnia da Corporação. A corporação é uma denominação que permite hipostaziar um grupo detentor de capital, ancorados por uma burocracia privada, manifestados em ações de inúmeras empresas, que forma um conglomerado de indivíduos que, independente da maneira que ocorre a organização da produção e a distribuição de mercadorias, irá se apropriar da riqueza social produzida por trabalhadores das mais diferentes regiões mundiais. Contudo, o autor demonstra que os grupos dominantes não estão apenas na burocracia privada, mas fazem parte da burocracia estatal.

Os "interesses econômicos hegemônicos" referem-se à classe dominante, ou seja, aos donos dos meios de produção e também à burocracia estatal. São os que detêm o domínio, o controle sobre o Estado em benefício de seus interesses, como instrumento de predomínio sobre toda a sociedade, que vai à contramão dos interesses da coletividade.

No que tange a universidade, Tragtenberg (2004, p. 15) demonstra que ela "[...] tende cada vez mais à adaptação indiscriminada a quaisquer pesquisas a serviço dos interesses econômicos hegemônicos". A produção de pesquisa dentro de uma universidade transforma-se em um meio de atender os "interesses econômicos hegemônicos", perdendo de vista a formação integral do ser humano: "É com o capitalismo que o saber instrumental adquire características dominantes" (ibidem, p. 21). Essa dominação decompõe a produção do saber, que acaba sendo apropriada ao mercado, e é essencial ao desenvolvimento das forças produtivas.

Maurício Tragtenberg, através de sua obra $A$ delinqüência acadêmica, nos mostra que as universidades estão inseridas em um sistema competitivo, destinadas à produção de um saber para atender as demandas dos setores dominantes da sociedade, onde não apenas se reproduzem os modos de produção capitalistas, pela transmissão de um saber ideológico, mas também pelos "servos que ela forma" 
(ibidem, p. 14). O que está em jogo é uma prática de dominação do conhecimento, objetivando formas alienadas do acesso ao saber.

Através do ensino e da pesquisa ocorre a apropriação do saber para a servidão aos interesses do capital. O conhecimento produzido dentro das estruturas burocratizadas é o saber aceito como legítimo e, dentro dessa construção institucionalizada, algumas teorias tornam-se hegemônicas, nesse processo, assumem caráter ideológico. Contudo, Tragtenberg salienta que a hegemonia não resulta da natureza do objeto estudado em si, mas da relação de interesse dos setores dominantes da sociedade. O que a teoria dominante guarda sob a aparência da neutralidade científica [ou do tão em voga relativismo pós-moderno] são os interesses das classes dominantes.

A universidade "é simplesmente uma instituição dominante ligada à dominação" (TRAGTENBERG, 2004, p. 12). Essa prática ocorreu e ainda ocorre em diferentes escalas, e tem como base a produção de um saber destinado à reprodução do poder.

No século XIX, período do capitalismo liberal, ela (a universidade) procurava formar um tipo de "homem" que se caracterizava por um comportamento autônomo, exigido por suas funções sociais: era a universidade liberal humanista e mandarinesca. Hoje, ela forma a mão de obra destinada a manter nas fábricas o despotismo do capital. Nos institutos de pesquisa, cria aqueles que deformam dados econômicos em detrimento dos assalariados; sua escola de direito forma os aplicadores de legislação de exceção; nas escolas de medicina, aqueles que irão convertê-la numa medicina do capital ou utilizá-la repressivamente contra os deserdados do sistema. Em suma, trata-se de "um complô de belas armas" recheadas de títulos acadêmicos, de doutorismo substituindo o bacharelismo, de uma nova pedantocracia, da produção de um saber a serviço do poder, seja ele de que espécie for (TRAGTENBERG, 2004).

Nesse sentido, e apontando especificamente para a educação, é possível verificar, segundo Tragtenberg (2004, p. 14), que a "apropriação universitária [atual] do conhecimento é a concepção capitalista de saber, na qual ele se constitui em capital e toma a forma nos hábitos universitários": a produção do saber transformase em uma maneira de capacitar um grande número de indivíduos para atuarem no setor produtivo, com o objetivo de servirem de mão-de-obra ao mercado de 
trabalho, através de uma concepção que esteja de acordo com os interesses da classe dominante, perdendo-se assim de vista a formação de um ser humano crítico e criativo. Tragtenberg (2004, p. 12), ainda, ressalta, "[...] os critérios lucrativos da empresa privada funcionarão para a formação das fornadas de 'colarinhos brancos' rumo às usinas, aos escritórios e às dependências ministeriais".

O diploma permite o acesso às novas tecnologias produtivas, atendendo as diretrizes do mercado de trabalho e, consequentemente, garantindo as condições de produção e reprodução da força de trabalho, que é um dos objetivos do Estado. Esse é o contexto do "mundo da realidade concreta", que acaba por comprometer a leitura da realidade em sua totalidade.

Estritamente, o mundo da realidade concreta é sempre muito generoso com o acadêmico, pois o título acadêmico torna-se o passaporte que permite $\mathrm{o}$ ingresso nos escalões superiores da sociedade: a grande empresa, o grupo militar e a burocracia estatal. O problema da responsabilidade social é escamoteado, a ideologia do acadêmico é não ter nenhuma ideologia, faz fé de apolítico, isto é, serve à política do poder (TRAGTENBERG, 2004, p. 17).

No âmbito das universidades, os efeitos da dominação se fazem sentir, entre outras coisas, pelo afastamento entre "fazer" e "pensar", pois conforme demonstra o autor: "O pensamento está fundamentalmente ligado à ação" (TRAGTENBERG, 2004, p. 17-18). Assim sendo, o ideal clássico de universidade, voltada para a pesquisa, a difusão da cultura, responsabilidade social, uma visão crítica da realidade, entra em colapso, pois

[...] a separação entre "fazer" e "pensar" se constitui numa das doenças que caracterizam a delinquência acadêmica - a análise e a discussão dos problemas relevantes do país constituem um ato político, constituem uma forma de ação, inerente à responsabilidade social do intelectual (TRAGTENBERG, 2004, p. 18).

Apenas para relembrar - no que se refere à educação superior no país e considerando a racionalidade econômica vigente - nos deparamos com um processo de ensino baseado no desenvolvimento de competências, que se assemelha ao sistema de ensino europeu de educação superior, constituído através dos parâmetros do Processo de Bolonha. O Processo de Bolonha nasceu a partir da Declaração de Bolonha de junho de 1999, um conjunto de acordos assinados 
pelos Ministros da Educação de 29 países da Europa. O processo refere-se às mudanças das políticas públicas do ensino superior com o compromisso dos países participantes na reorganização do sistema de ensino superior, com base nos princípios estabelecidos da declaração. A questão central no Processo de Bolonha é o da

[...] mudança do paradigma de ensino de um modelo passivo, baseado na aquisição de conhecimentos, para um modelo baseado no desenvolvimento de competências, onde se incluem quer as de natureza genérica - instrumentais, interpessoais e sistêmicas - quer as de natureza específica associadas à área de formação, e onde a componente experimental e de projecto desempenham um papel importante (DecretoLei n. 74/2006, p. 2).

Destarte, trata-se de focar no agir, segundo demandas do capital. Diante das referidas reformas e processos, vemos que naturalmente atendem aos interesses do setor produtivo e políticos dominantes, decompondo a formação integral do ser humano. Afinal, como destaca Tragtenberg (2004, p. 204) "a educação não pode estar acima da estrutura socioeconômica que a determina" e ainda salienta:

\begin{abstract}
A delinquência acadêmica caracteriza-se pela existência de estruturas de ensino em que os meios (técnicas) se tornam fins, os fins formativos são esquecidos; a criação do conhecimento e sua reprodução cedem lugar ao "controle" burocrático de sua produção como suprema virtude, em que "administrar" aparece como sinônimo de vigiar e punir - o professor é controlado mediante os critérios visíveis e invisíveis de nomeação; o aluno, mediante os critérios visíveis e invisíveis de exame. Isso resulta em escolas que se constituem em depósitos de alunos, como diria Lima Barreto em "Cemitério de vivos". (Tragtenberg, 2004, p. 18).
\end{abstract}

Destacamos que à nomeação agregaram-se outras formas de controlar o professor-pesquisador. Na última década, acompanhamos a implementação e intensificação dos processos avaliativos da produção docente. Os "critérios Capes", que transformam todo o produto em pontos, a despeito da qualidade dos mesmos, permitem expandir as considerações de Tragtenberg (2004, p. 24) a respeito do cientista social a outras especialidades. Para o autor, "O sociólogo acadêmico produz como um operário de linha de produção; não discute os fins, o resultado é a alienação. Por outro lado, utiliza nos seus estudos os fundamentos que garantem a estabilidade dos sistemas [...]" e, nesse sentido, segue precarizando sua própria condição de trabalho que, consequentemente, atinge a saúde do trabalhador intelectual.

Cad. de Pesq. Interdisc. em Ci-s. Hum-s., Florianópolis, v.13, n.103, p.115-145, ago/dez 2012 
Queremos destacar que não se advoga a favor do fim dos processos avaliativos, até mesmo porque estes são um mecanismo de controle social acerca do resultado dos destinos dado ao fundo público, enquanto financiamento para o desenvolvimento de pesquisas. Ou seja, avaliar para quê e como um valor monetário social é utilizado, trata-se de um interesse coletivo. O que indagamos é o endereçamento desse fundo. Como ele é canalizado para atender interesses do capital - conforme já observamos na discussão com Oliveira -, ele só pode ser controlado segundo critérios de rentabilidade do mesmo, ou seja, pela intensificação da produtividade. Nesse sentido, tão relevante quanto problematizarmos os critérios de avaliação é refletirmos em nome dos interesses de quem essa avaliação é efetuada - ou, como diria Tragtenberg (2004, p. 17), "conhecimento a quem e para que serve?". A reposta a essa indagação revela os agentes que determinam os critérios, apesar da existência de espaços para os pares da academia debaterem e deliberarem acerca dos mesmos. Todavia, esses são apenas a prática da suposta participação democrática ou, como mencionaria Tragtenberg, da ideologia participacionista.

Além da intensificação da produção no meio acadêmico, presenciamos o fundo público condicionando a participação efetiva de pesquisadores nas empresas, destinando, sem mediação, a produção do conhecimento para a apropriação privada. Podemos citar como exemplos de utilização do fundo público para este fim alguns editais para concessão de bolsas da Capes (Coordenação de Aperfeiçoamento de Pessoal de Nível Superior) e do CNPq (Conselho Nacional de Desenvolvimento Científico e Tecnológico) como: Plano Nacional de Pós-Doutorado - PNPD; Pós-Doutorado Empresarial - PDI; Doutorado-Sanduíche Empresarial SWI, conforme resume quadro a seguir. 


\begin{tabular}{|c|c|c|c|}
\hline EDITAL: & $\overline{\text { PNPD }}$ & PDI & SWI \\
\hline ÓRGÃO: & CAPES & $\mathrm{CNPq}$ & CNPq \\
\hline FINALIDADE & $\begin{array}{l}\text { Possibilitar a integração } \\
\text { de pesquisas } \\
\text { desenvolvidas entre } \\
\text { universidades e } \\
\text { empresas. O programa } \\
\text { estimula a atuação de } \\
\text { recém-doutores em } \\
\text { projetos de } \\
\text { desenvolvimento } \\
\text { científico em áreas } \\
\text { estratégicas, a } \\
\text { formação de recursos } \\
\text { humanos e a inovação } \\
\text { tecnológica. }\end{array}$ & $\begin{array}{l}\text { Possibilitar ao } \\
\text { pesquisador a } \\
\text { consolidação e } \\
\text { atualização de seus } \\
\text { conhecimentos, assim } \\
\text { como agregar } \\
\text { competência às ações } \\
\text { de pesquisa, } \\
\text { desenvolvimento e } \\
\text { inovação de empresa } \\
\text { no país, com vistas à } \\
\text { melhoria de sua } \\
\text { competitividade. }\end{array}$ & $\begin{array}{l}\text { Apoiar aluno } \\
\text { formalmente } \\
\text { matriculado em curso } \\
\text { de doutorado no } \\
\text { Brasil, que necessite } \\
\text { complementar a sua } \\
\text { formação } \\
\text { participando de } \\
\text { ações de pesquisa, } \\
\text { desenvolvimento e } \\
\text { inovação em } \\
\text { empresa no País. }\end{array}$ \\
\hline
\end{tabular}

Quadro 1: Finalidades bolsas Capes e CNPq

Fonte: Elaborado pelas autoras, a partir de PROGRAMA Nacional de Pós-Doutorado, s/d; DOUTORADO Sanduíche Empresarial, s/d e ANEXO VII da RN-016/2006.

A finalidade destas modalidades de bolsas evidenciam, per si, nossas considerações quanto ao interesse privado ser beneficiado pela alocação do fundo público, sobretudo em afirmações como "à melhoria de sua competitividade" (ANEXO, 2006). Dentre os requisitos, destacamos a necessidade do pós-doutor "[...] c) dedicar-se integralmente às atividades programadas na empresa de destino"(ibidem). As bolsas têm duração de 6 a 24 meses e os benefícios são, além do recurso em espécie, auxílio moradia e passagem aérea, quando necessários.

Outra medida recente libera mão-de-obra barata para o setor privado: trata-se da Conjunta Capes/CNPq n 01 de 15/07/2010. Esta autoriza o acúmulo de bolsas de mestrado e doutorado com vínculo empregatício, desde que adquirido já na condição de aluno-bolsista das referidas instituições. Segundo nota divulgada em sítio eletrônico das duas instituições, consultado no dia 17 de abril de 2011, os presidentes da Capes e CNPq, respectivamente, Jorge Almeida Guimarães e Glaucius Oliva, esclarecem:

Além disso, essa Portaria possui como principal objetivo induzir a formação de mestres e doutores em áreas estratégicas nas quais é academicamente desejável a maior aproximação do pós-graduando com o mercado, tais como engenharias, ciências agrárias, biotecnológicas, computação, serviços em saúde e educação básica.

Refletindo sobre as modalidades de concessão de bolsa e a supracitada portaria, é possível concordar com Tragtenberg (2004) acerca da produção de Cad. de Pesq. Interdisc. em Ci-s. Hum-s., Florianópolis, v.13, n.103, p.115-145, ago/dez 2012 
um saber para a perpetuação da dominação. O Estado induz, por meio de suas políticas, a produção de conhecimentos que atendam aos interesses de empresas de determinados setores econômicos, tendo em vista que as atividades de pesquisa devem estar intrinsecamente relacionadas às atividades profissionais realizadas no interior da iniciativa privada. Disto resultam relatórios, teses, dissertações que produzem um conhecimento específico, mas que por "ser ciência" é generalizável e ensinado nas salas de aulas das universidades, fechando o ciclo da construção de um saber enquanto saber dominante. Por homologia, podemos inferir que o fundo público na forma de bolsas de estudo apresentadas acima possibilita a formação de inúmeros "Elton Mayo".

Sem atentarmos para os reais beneficiários dessas bolsas, permanecemos deixando na obscuridade o processo da transmutação do interesse privado em interesse coletivo. Deixamos de atentar para o fato de que essas bolsas possibilitam a criação das condições para que o poder produza "um tipo de saber necessário à dominação" e que este, ao ser "aplicado reproduz o poder" (TRAGTENBERG, 2004, p. 21).

Ademais, diferente da regulamentação da Lei $n^{\circ}$ 10.973/2004, essas medidas não restringem a nacionalidade do capital, em suma, trata-se do fundo público subsidiando o capital estrangeiro pelo fornecimento de mão-de-obra. Por outro lado, é possível pensar em uma desmercantilização de parte da força de trabalho deste operário-estudante especializado e altamente capacitado. A bolsa de estudo passa a atuar como um salário indireto e a remuneração proveniente das atividades realizadas profissionalmente como o salário direto que, por sua vez, não necessita ser equivalente ao valor da mercadoria vendida, em função do subsídio estatal. Além disso, é patente que a possibilidade de acúmulo desloca a discussão acerca dos valores das bolsas no país para a procura individual por trabalho que permita a complementação da renda do bolsista.

Disso, resulta um questionamento: se a empresa carece de mão-de-obra qualificada para o desenvolvimento e implantação de inovações para se manter competitiva, por que ela não emprega tal trabalhador? Segundo Oliveira, esse é um indício que tende a corroborar a impossibilidade do lucro capitalista concretizar as novas possibilidades de progresso técnico sem recorrer ao fundo público. Por outro lado, a permanência de profissionais altamente qualificados na condição de bolsista 
revela a precarização das relações de trabalho no Brasil. Eis outro ponto que carece ser discutido com maior acuidade.

A existência desses editais possibilita exemplificar a utilização do fundo público para atender as necessidades e os interesses da classe dominante. Alguns órgãos de fomento estatais são empregados como mecanismo de manipulação de tais interesses, em que a produção de um conhecimento deixa de priorizar o saber reflexivo e emancipatório e passa a ser condicionante da alienação e, consequentemente, atua em prol do desenvolvimento e crescimento da produção. Portanto, muitas vezes, é através da dominação do saber que a reprodução das relações de produção acontece, conforme já mencionara Tragtenberg. Esta é uma ideologia que passa despercebida, pois o capitalismo moderno imprescinde da instrumentalização do saber, de sua neutralidade ou de sua relatividade, de modo que uma das responsabilidades inerentes ao intelectual - a discussão política - é rechaçada. A educação começa a perder até mesmo sua conotação ideada de "ideologia libertadora" que promove a formação intelectual e a consciência crítica do indivíduo, e passa a seguir os ditames do mercado, funcionando a sua semelhança. Deste modo, o fundo público é destinado à produção de um conhecimento que funciona como substrato para a ideologia dominante. Ressaltamos, no entanto, que a mesma realidade que cria o academicismo cria sua negação (TRAGTENBERG, 2004 , p. 42), ou seja, o mesmo fundo público que opera como mecanismo ideológico para a perpetuação do capital, também cria sua negação (ou tentativa de), como é o caso deste texto que foi elaborado em função do debate oriundo de uma pesquisa financiada por um convênio firmado entre o Instituto de Pesquisa Econômica e Aplicada e a CAPES.

Mudaram-se as condições da circulação de capitais, ao estabelecer regras de funcionamento do elemento estruturante da acumulação - o fundo público. Assim, as inúmeras formas de incentivo financeiro à disposição da iniciativa privada condicionam e são condicionadas pelos campos de atuação das mesmas, conforme correlação das forças políticas em questão. As diversas formas de incentivo muitas vezes são ocultadas com discursos que divulgam o desenvolvimento social, porém, no caso da ciência e tecnologia, estão associadas à produção de um saber tecnicista, destinado à acumulação. Compreender essa ocultação é imprescindível 
para atuarmos criticamente e é possível através dos estudos de Tragtenberg e Oliveira.

\section{Resultados e Análises}

As contribuições dos autores possibilitam entendermos o incentivo ao desenvolvimento científico e tecnológico, sobretudo aquele que resulta em inovações, operado por meio do modelo da Hélice Tríplice, como manifestação do duplo papel do fundo público, qual seja: econômico - elemento estrutural para a acumulação do capital; e ideológico - elemento que possibilita a construção de um saber que sustenta a dominação. Disso decorre afirmarmos que a empresa (iniciativa privada) tem se estabelecido como o conceito intercambiável ao de sociedade. Identificado isso, resta-nos ainda a questão inicial: como se processa o movimento de particularização dos interesses gerais da sociedade no ente privado?

O fundo público, por meio do modelo Hélice Tríplice, opera como mecanismo econômico e ideológico para perpetuação do sociometabolismo do capital, mas sob a aparência de estar atendendo aos interesses coletivos. Na superfície das relações estabelecidas entre academia-empresa-Estado, a empresa transmuta-se em agente mediador entre Estado e Sociedade, por "representar" os interesses da última enquanto agente destinatário do saber produzido nas universidades com o incentivo estatal. Perguntar como se processa o movimento de particularização dos interesses gerais é, após o diálogo com as considerações de Tragtenberg e Oliveira, para nós, um falso problema. Para explicar tal afirmação, necessitamos apresentar o que entendemos por Estado e Ideologia.

Estado é aqui compreendido como a forma que uma determinada organização social adquire, corporificado na burocracia, ao mediar a relação entre interesses particulares sob a forma de interesses gerais. Desse modo, a sociedade civil é entendida como o espaço dos interesses privados enquanto que o Estado é entendido como uma totalidade, que visa atender o universal, conservando os particulares. É o caráter de universalidade do Estado que permite que este transfira o dever de operacionalizar os interesses gerais a certos agentes da sociedade civil, no caso aqui apresentado, as empresas. 
Acontece que, conforme nos mostra Marx e Engels (2007, p. 75-6), o Estado não opera, a não ser idealmente, a transmutação dos interesses particulares em geral:

[...] esse Estado não é nada mais do que a forma de organização que os burgueses se dão necessariamente, tanto no exterior como no interior, para a garantia recíproca de suas propriedades e de seus interesses [...] Como o Estado é a forma na qual os indivíduos de uma classe dominante fazem valer seus interesses comuns e que sintetiza a sociedade civil inteira de uma época, segue que todas as instituições coletivas são mediadas pelo Estado, adquirem por meio dele uma forma política.

Os interesses particulares da classe dominante são idealmente transformados em gerais no âmbito do Estado e das suas instituições, das quais destacamos as universidades. Por serem ideias dominantes, "[...] refletindo os interesses das classes dominantes [...] assumem caráter ideológico" (TRAGTENBERG, 2006, p.19).

Segundo as exposições de Tragtenberg, a ideologia é um conjunto de ideias que oferece sentido aparente às relações sociais concretas, a fim de perpetuar a transubstancialização de interesses particulares à interesses gerais. As ideologias guardam correspondência com as condições materiais de reprodução da vida, caso assim não fosse, não se sustentariam por muito tempo; entretanto, seu poder explicativo não ultrapassa certo horizonte intelectual (LÖWY, 1994), este determinado pelos interesses da classe dominante, tendo em vista que:

[...] a classe que é a força material dominante da sociedade é, ao mesmo tempo, sua força espiritual dominante. [...] Os indivíduos que compõem a classe dominante possuem, entre outras coisas, também, consciência e, por isso, pensam; na medida em que dominam como classe e determinam todo o âmbito de uma época histórica é evidente que eles fazem em toda sua extensão, portanto, entre outras coisas, que eles dominam também como pensadores, como produtores de idéias, que regulam a produção e a distribuição das idéias de seu tempo; e, por conseguinte, que suas idéias são as idéias dominantes da época (MARX e ENGELS, 2007, p. 47).

A divisão social do trabalho fornece à classe dominante os pensadores que a servem e, à medida que fazem parte do corpo burocrático estatal, parecem produzir em nome dos interesses gerais. Convêm observar que "[...] tudo é visto pela ótica do aparelho de Estado e dos órgãos governamentais. Os intelectuais fazem parte integrante do complexo militar-industrial-acadêmico" (TRAGTENBERG, 2004, p. 
22). Ocorre que o Estado constitui-se como um conjunto de múltiplos agentes que opera em prol do capital e está comprometido em legitimar o seu movimento.

\section{Considerações Finais}

O modelo Hélice Tríplice apenas (re)afirma, sob um discurso universalizante, que o Estado - enquanto lócus de conservação das ideias das classes que detêm os meios de produção -, está conectado com a manutenção de uma ordem estabelecida que, em sua essência, não é representante dos interesses da coletividade social e, sim, comprometida com os compromisso de ampliação da mais valia, tornando as empresas destinatárias do saber produzido nas instituições públicas de ensino superior, sendo esse o aspecto determinante. Eis porque o movimento de particularização dos interesses gerais no ente privado empresa é um falso problema.

No entanto, como mencionamos, a ideologia somente se perpetua se guardar relativa correspondência com os meios materiais que a produz e, nesse sentido, o Estado não é pura e simplesmente o defensor dos interesses da classe burguesa; ele também é mediador nas relações entre as classes, pois somente assim pode permanecer enquanto totalidade. Desse modo, salientamos que se faz necessário problematizar o uso do fundo público enquanto mecanismo ideológico, para que o processo de produção desse movimento revele o processo no que ele é: luta de classes e, por consequência, coloque-se em pauta um problema verdadeiro: "Resta resolver um problema, intacto, que é o da apropriação dos resultados desse modo social" (OLIVEIRA, 1998, p. 36). Aqui carecemos dar destaque a dois desdobramentos, quais sejam: a existência de interesses de grupos distintos intraclasse capitalista e os interesses antagônicos entre classes (capitalistas e trabalhadores).

Em virtude da existência de inúmeros interesses distintos intraclasse, não basta ser um empresário para beneficiar-se do fundo público. Como é demonstrado na Portaria Conjunta Capes/CNPq n ${ }^{\circ} 01$ de 15/07/2010, são determinados setores econômicos os agraciados com facilidades de acesso ao produto do trabalho social. Nesse sentido, um estudo detalhado da destinação dos fundos públicos pode vir a revelar as relações de poder entre os grupos da classe burguesa e suas 
alternâncias, conforme grupo político no governo, ou seja, pode trazer à tona os grupos dominantes à época, os quais vão se alternando no decurso do tempo.

Concordamos, portanto, com Oliveira que esclarece que o fundo público necessita ser problematizado enquanto um móvel de luta entre as classes sociais. Para ele, esfera pública e democracia são sinônimos nos países capitalistas, sendo a democracia representativa do espaço institucional onde todas as classes intervêm a fim de que se constitua o público acima do privado, e que tanto a democracia representativa como a esfera pública devem afirmar as classes sociais como expressões coletivas e sujeitos da história. Ressaltamos, todavia, que Oliveira não exclui a luta de classes no âmbito da relação direta entre capitalistas e trabalhadores. Ele apenas atenta para o fato que a mesma também ocorre por meio da disputa pelo fundo público.

A (re)distribuição do fundo público torna-se, portanto, móvel de luta entre as classes por ser uma apropriação estatal do resultado do trabalho social que, sem a pressão da classe trabalhadora, tende a ser destinado ao atendimento dos interesses da classe capitalista, em função da própria natureza do Estado burguês; natureza que se revela no modelo Hélice Tríplice: academia-empresa-governo rodando sobre um mesmo eixo (o eixo dos interesses privados), que tende a propulsionar apenas o corpo que compõe (interesses econômicos de uma classe) pelo deslocamento dos que estão a sua volta (interesse geral da classe trabalhadora). Nesse sentido, demonstra-se necessário frear o movimento dessa hélice ou, como diria Tragtenberg (2004, p. 107):

Em suma, trata-se de se fazer ciência, produzir conhecimentos e não apenas teses sobre o irrelevante que garantam um lugar ao sol ao futuro acadêmico. Para que isso ocorra é necessário perder o terror da crítica, o medo de questionamentos e da repressão que o acompanha. É claro que isso tudo exige o básico: a organização da sociedade civil em relação à sociedade política (o Estado) e a transformação do "súdito tributário" em cidadão, impossível sem a liberdade da auto-organização dos assalariados de todo tipo [inclusive o subproletariado intelectual]. 


\section{REFERÊNCIAS}

ALVES, G. O novo (e precário) mundo do trabalho: reestruturação produtiva e crise do sindicalismo. São Paulo: Boitempo, 2000.

ANEXO VII da RN-016/2006, 2006. Disponível em: <http://cnpq.br/documents/10157/8c6d1438-dfe2-4713-8739-7a90db3121e6>. Acesso em: 17 abr. 2011.

BORGES, M. N. Vale o Investimento! Revista Techoje, IETEC - Instituto de Educação Tecnológica, 2010. Disponível em: <http://www.ietec.com.br/site/yechoje/categoria/abrirPDF/815>. Acesso em: 17 abr. 2011.

DOUTORADO SANDUÍCHE EMPRESARIAL. CNPq. Disponível em: <http://www.cnpq.br/normas/rn 06016 anexo8.htm>. Acesso em: 17 abr. 2011.

GIELH, P. R. Fundopem: instrumento público de descentralização ou de reforço à concentração industrial no Rio Grande do Sul? Dissertação (Mestrado em Administração) - Universidade Federal do Rio Grande do Sul, Porto Alegre, 2001. Disponível em: <http://hdl.handle.net/10183/1986>. Acesso em: 12 nov. 2009.

IBGE, Instituto Brasileiro de Geografia e Estatística. Censo. Brasília: [s/e], [s/d]. Disponível em: <http://www.ibge.gov.br/home/download/estatistica.shtm>. Acesso em: 15 jul. 2011.

INOVAÇÃO Tecnológica. Lei de Inovação começa a valer, 2005. Disponível em: $<$ http://www.inovacaotecnologica.com.br/noticias/noticia.php?artigo $=010175051018>$ Acesso em: 18 abr. 2011.

KAPRON, S. R.; LENGLER, F. Fundopem, investimentos públicos e empregos na indústria gaúcha. In: $3^{\circ}$. Encontro de Economia Gaúcha, Porto Alegre, 2006.

Disponível em: <http://www.fee.com.br/3eeg/Artigos/m14t04.pdf>. Acesso em: 20 set. 2009.

LEI $n^{\circ} 10.973$, de 2 de dezembro de 2004. Disponível em: $<$ http://www.planalto.gov.br/ccivil 03/ ato2004-2006/2004/Lei/L10.973.htm>. Acesso em: 10 abr. 2011. 
LEI n. 74/2006. In: Diário da República - I Série A, n.60 de 24 de março de 2006. Disponível em: <http://www.mctes.pt/?idc=31\&idi=163\&idt=22>. Acesso em: $17 \mathrm{abr}$. 2011.

LÖWY, M. As aventuras de Karl Marx contra o Barão de Münchhausen:

Marxismo e Positivismo na Sociologia do Conhecimento. São Paulo: Cortez, 1994.

MARX, K.; ENGELS, F. A ideologia alemã. São Paulo: Boitempo, 2007.

MAULER, R. S. et al. Parque científico e tecnológico: proposta de implantação, 2009. Disponível em:

$<$ http://paginas.ufrgs.br/parquetec/documentos/PropostaOutubro 2009.doc/view>. Acesso em: 16 abr. 2011.

OLIVEIRA, Francisco de. Os direitos do antivalor: a economia política da hegemonia imperfeita. Petropólis: Vozes, 1998.

OLIVEIRA, Francisco de. Crítica à razão dualista/O ornitorrinco. São Paulo: Boitempo, 2003.

PORTARIA CONJUNTA CAPES CNPq $\mathrm{n}^{\circ} .01$ de 15/07/2010. Disponível em: $<$ http://ebookbrowse.com/arq-portaria-conjunta-capes-cnpq-n-1-de-15-07-2010-61pdf-d77549777>. Acesso em 17 abr. 2011.

PÓS-DOUTORADO EMPRESARIAL, CNPq. Disponível em: <http://www.cnpq.br/normas/rn 06016 anexo7.htm>. Acesso em: 17 abr. 2011.

PROGRAMA NACIONAL DE PÓS-DOUTORADO, PNPD, CAPES. Disponível em: $<$ http://www.capes.gov.br/bolsas/bolsas-no-pais/2190M>. Acesso em 17 abr. 2011.

TRAGTENBERG, M. Sobre Educação, Política e Sindicalismo. $3^{a}$. ed. São Paulo: Editora Unesp, 2004.

TRAGTENBERG, M. Administração, poder e ideologia. São Paulo: Editora Unesp, 2005.

TRAGTENBERG, M. Burocracia e ideologia. $2^{\text {a }}$. ed. São Paulo: Editora Unesp, 2006. 
Artigo:

Recebido em: 07/05/2012

Aceito em: 21/12/2012 